\title{
Different Terms Fluctuations of Solar Power System
}

\author{
Yindong $\mathrm{Liu}^{1,2}$, Changchun $\mathrm{Hu}^{2}$, Miao $\mathrm{MiaO}^{3}$, Fei Peng ${ }^{3}$ \\ ${ }^{1}$ School of Electrical Engineering, Shenyang University of Technology, Shenyang 110870, China \\ ${ }^{2}$ School of Automation Engineering, Northeast Electric Power University, Jilin 132012, China
}

${ }^{3}$ Economic Research Institute, State Grid Qinghai Electric Power Company, Xining 810008, China

Keywords: Solar Power System; Generation Fluctuations; Different Terms; Fluctuation Level; Random Distribution

\begin{abstract}
The generation of solar power are known to be seriously influenced by many factors, such as temperature, humidity, et al. These factors cause the fluctuations of solar power system. This paper considers those fluctuations of different terms by using actual historical data and the different distribution method. From the analysis and simulations, we find the fluctuation data for different terms can fit different kinds of distribution functions, such Gaussian distribution, $\mathrm{T}$ Location-scale, Histogram distribution, and Logistic distribution. Finally, the simulation shows the method is effective and efficient.
\end{abstract}

\section{Introduction}

Nowadays, the utilization of renewable energy in the power system has deeply developed. The solar system has a priority. For example, these renewable energies will share of $20 \%$ of the total energy consumption by 2020 and $60 \%$ by 2050 [1]. As knows, these renewable sources are highly fluctuating for different time scales, see [2,3] and reference therein. For safety reason, we must handle the situation and forecast the fluctuations and control them.

In traditional power plants, the inertia of fast rotating generators is utilized as an automatic power reserve. This is done simply by speeding up or slowing down the rotating masses, keeping the grid frequency within a narrow range around the nominal frequency. In the ENTSO-E $\neq$ grid, the value of the nominal frequency is $50 \mathrm{~Hz}$ and the tolerated deviation from this value is $\pm 10 \mathrm{MHz}$ [4]. Restoring the grid frequency to the nominal frequency, in current practice, is provided by traditional frequency control, which has three categories: primary, secondary and tertiary frequency control, cf. [5]. The primary frequency control is provided within a few seconds after the occurrence of a frequency deviation. It provides extra power for stabilizing the system frequency (but not restoring it to the nominal frequency [6]. The secondary frequency control acts after approximately $30 \mathrm{~s}$ and restores both the grid frequency from its residual deviation and the corresponding tie-line power exchanges with other control zones to the set-point values. Tertiary frequency control manually adapts power generation and load set-points and controls the grid operation beyond the initial 15 minutes' time-frame after a fault event has occurred.

In the background of replacing the successively controllable conventional power plants by intermittent renewable power systems, there are several recent works studying the grid stability under these new constraints [7-9]. One practical approach is that synchronous machines of old power plants are still connected to the grid and providing the reactive power and inertia [10]. It has also been a practical topic to study how the stability of the power grid can be kept in the lower rotational inertia case (because of high penetration of renewable sources) using some faster control reserves $[11,12]$. One possible option is to use battery storage providing primary control reserve, see e.g. [13] for a very recent study on this topic.

PV output is affected by weather severely [1], when cloudy or overcast weather, the PV output will appear violent fluctuations. [2-5] points out that the fluctuation of PV output is harmful to the safety and stability of power grid. [6-8] propose that using energy storage equipment, the output fluctuation of photovoltaic or wind power can be smoothed by a certain control strategy. Literature [9] comes to the conclusion that when PV output appear large climbing rate, the irradiance curve 
closer to the PV output curve at $1 \mathrm{H}$ time scale through the statistical analysis of 100 photovoltaic power system data, the satellite irradiance data and meteorological data in San Diego County of the U.S. state of California. [10] Compares and analysis of the relevant provisions of the power quality in photovoltaic grid connected standards at home and abroad. [11] Points out that the probability distribution of wind power fluctuation characteristics can be described by the $t$ distribution ( $t$ location-scale) with the shift factor and the expansion coefficient. [12] Points out that Gauss mixture distribution model is used to fit the rate of wind power variation, which has a good effect on the probability density. The distribution characteristics of wind power fluctuation at different time and spatial scales are analyzed quantitatively in [13].

In this paper, based on a large number of statistical calculations of the historical data of photovoltaic power station using MATLAB software, the fluctuation of PV output is analyzed deeply. The fluctuation level of PV output is analyzed quantitatively, and the probability density fitting of various distribution functions is carried out by using the fluctuation data of the PV output at different time scales, and compare the fitting effect and research PV output fluctuations characteristic of random distribution.

\section{Influence of the Output Fluctuations of Grid Connected Photovoltaic Power Generation on Power Grid}

The fluctuation of photovoltaic is one of the important reasons that affect the development of photovoltaic, and the influence of output fluctuation of grid connected photovoltaic power generation on power grid is mainly reflected in the following aspects:

(1) Effect on power quality. When the PV output fluctuation reaches a certain level, it will cause the obvious fluctuation of the power grid voltage, also have a certain impact on frequency of the power grid, when the PV output becomes small, the output of the grid connected inverter is light load, and the current harmonic is increased.

(2) Impact on power grid planning. PV output has fluctuation and its fluctuation is random, which cannot meet the requirements of power supply stability, continuity and reliability of power grid, the power grid needs to have enough spinning reserve to adjust, while the fluctuations of PV output will cause a certain degree of transmission and distribution equipment capacity waste, which brings the challenge to the rational planning of grid.

(3) Influence on power grid operation and scheduling. In order to ensure the stability of power grid operation and power quality, it is required to suppress the fluctuations of PV output and put forward higher requirements to the operation control of power grid. PV output fluctuations caused load forecast certain difficulties, increasing the difficulty of the power grid scheduling.

In order to reduce the impact of PV output fluctuations on the power grid, set strict requirements for grid-connected PV power fluctuations, table 1 and table 2 are the national standard and the enterprise standards of State Grid Corporation of China (SGCC) respectively which is aimed at grid connected photovoltaic power fluctuation.

Table1 Technical regulation of grid connected photovoltaic power fluctuation in national standard ${ }^{[14]}$

\begin{tabular}{ccc}
\hline $\begin{array}{c}\text { Installed capacity of } \\
\text { photovoltaic power } \\
\text { generation/MW }\end{array}$ & $\begin{array}{c}\text { Maximum limit of active power in } \\
10 \mathrm{~min} / \mathbf{M W}\end{array}$ & $\begin{array}{c}\text { Maximum limit of active } \\
\text { power in 1min/MW }\end{array}$ \\
\hline$<30$ & 10 & 3 \\
$30 \sim 150$ & Installed capacity/3 & Installed capacity/10 \\
$>150$ & 50 & 15 \\
\hline
\end{tabular}


Table2 Technical regulation of grid connected photovoltaic power fluctuation in SGCC enterprise standard ${ }^{[15]}$

\begin{tabular}{|c|c|c|}
\hline Type of power station & $\begin{array}{l}\text { Maximum limit of active power in } \\
10 \mathrm{~min} / \mathrm{MW}\end{array}$ & $\begin{array}{l}\text { Maximum limit of active } \\
\text { power in 1min/MW }\end{array}$ \\
\hline $\begin{array}{c}\text { Small } \\
\text { Medium } \\
\text { Large }\end{array}$ & $\begin{array}{l}\text { Installed capacity } \\
\text { Installed capacity } \\
\text { Installed capacity/3 }\end{array}$ & $\begin{array}{c}0.2 \\
\text { Installed capacity/5 } \\
\text { Installed capacity/10 }\end{array}$ \\
\hline
\end{tabular}

In table 2, the type of power station is divided according to the voltage level of the photovoltaic power station connected to the power grid, small, medium and large photovoltaic power plants connected to the grid photovoltaic power plant respectively through $380 \mathrm{~V}, 10 \mathrm{kV} \sim 35 \mathrm{kV}, 66 \mathrm{kV}$ and above voltage. From table 1 and table 2 can be seen that the technical requirements of photovoltaic power fluctuations of national standards are more stringent relative to the national Power Grid Corp enterprise standards.

\section{The Fluctuation Level of PV Output}

In this paper, a 40MWp photovoltaic power plant is used as a sample to analyze the annual output active power data. Since PV output only in the daytime, at night, it does not contribute, so need to intercept the PV output data. Interception of the PV output data of the daily 5:30 19:30 light period for analysis.

Figure 1 is an output curve graph of photovoltaic power station of one day, it can be seen from the figure, PV output has obvious volatility, fluctuation can exceed $50 \%$ of the installed capacity in short time.

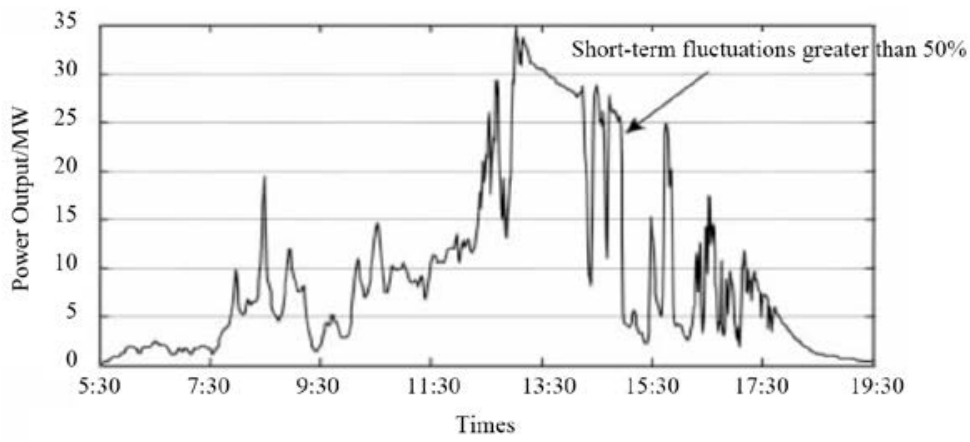

Fig.1. The output curve of PV power station in one day

Figure 2 is the single day output curve under sunny ,cloudy, overcast, rain and snow four different types of weather of photovoltaic power station , it can be seen that the weather has a significant impact on the level of fluctuations in the PV output, when sunny weather PV output is stable, when cloudy and overcast weather affected by cloud cover, PV output has a larger fluctuation, fluctuation can exceed $50 \%$ of the installed capacity in short time, when rainy and snow weather , the overall level of photovoltaic output is very low, the output fluctuation is smaller than that of cloudy and overcast weather.

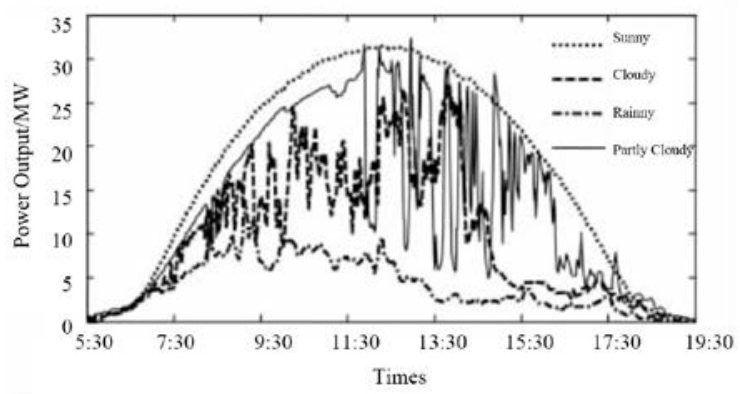

Fig.2. The PV output curves under different weather 
Table 3 Statistics for Maximum fluctuation of PV output at $1 \mathrm{~min}, 10 \mathrm{~min}, 60 \mathrm{~min}$ three-time scale. It can be seen that with the increase of time scale, the maximum fluctuation of PV output is also increased. The maximum PV output fluctuation of $1 \mathrm{~min}$ and $10 \mathrm{~min}$ time scale seriously exceeds the national standard for grid connected PV output power change regulation range.

Table3 Maximum fluctuation of PV output at different time scales

\begin{tabular}{cc}
\hline Time scale/min & Maximum fluctuation/MW \\
\hline 1 & 16.10 \\
10 & 29.74 \\
60 & 34.54 \\
\hline
\end{tabular}

\section{Random Distribution Characteristics of PV Output Fluctuation}

The fluctuation condition of PV output can be described by the 1 order difference component of the active power of the PV output, 1 order difference component is the output power difference of the adjacent sampling point. In this paper, the probability density function is used to describe the randomness of PV output fluctuation. Probability density fitting of 3 kinds of distribution functions to the PV output fluctuation data at different time scale and comparison and analysis. Formula (1) (3) respectively give the probability densities expressions of the normal distribution, $t$ location scale distribution and logistic distribution.

$$
f(x)=\frac{1}{\sigma_{1} \sqrt{2 \pi}} e^{\frac{-\left(x-u_{1}\right)^{2}}{2 \sigma_{1}^{2}}}
$$

Here $\mathrm{u}_{1}$ is the mean value and $\sigma_{1}$ is variance.

$$
f(x)=\frac{\Gamma(v+1 / 2)}{\sigma_{2} \sqrt{v \pi}(v / 2)}\left[\frac{v+\left(x-u_{2} / \sigma_{2}\right)^{2}}{v}\right]^{-v+1 / 2}
$$

Here $u_{2}$ is position parameter, $\sigma^{2}$ is scale parameter and $v$ is shape parameter.

$$
f(x)=\frac{e^{-\frac{x-u_{3}}{\sigma_{3}}}}{\sigma_{3}\left(1+e^{-\frac{x-u_{3}}{\sigma_{3}}}\right)^{2}}
$$

Here $u_{3}$ is position parameter and $\sigma_{3}$ is scale parameters.

Figure 3 are the PV output fluctuation probability density curves of the PV output fluctuation data which is fitted respectively by the normal distribution, $t$ location-scale distribution and logistic distribution at $1 \mathrm{~min}, 10 \mathrm{~min}, 60 \mathrm{~min}$ time scales.

In order to evaluate the fitting effect of probability density, the reasonable evaluation index is defined. The expression is:

$$
I=d^{2} \sum_{i=1}^{n}\left(y_{i}-m_{i}\right)^{2}
$$

In the formula: $d$ is the group distance of the frequency distribution histogram, $i=1,2, \ldots, n ; n$ is the number of packets in the histogram; $y_{i}$ is the fitting probability density value of the $i$ th center position of rectangular column; $m_{i}$ represents the height of the ith rectangular column of data frequency distribution histogram .The smaller the indicator I, the better the effect.

Table 4, Figure 4 statistics of the fitting index comparison of PV output fluctuation probability density which is fitted by the normal distribution, $t$ location-scale distribution and logistic distribution at different time scales. 


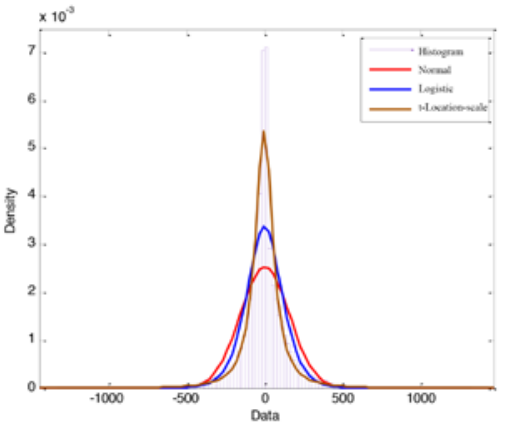

(a) 1-minute time scale

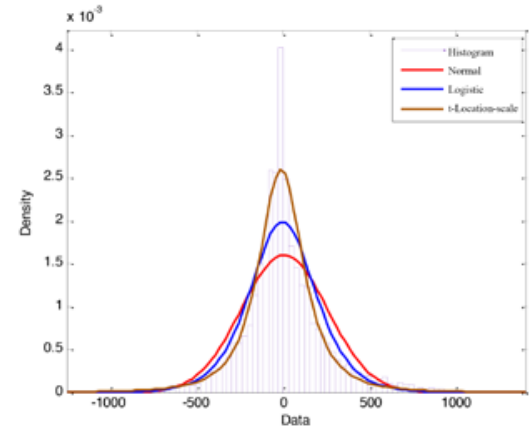

(b) 10 minutes' time scale

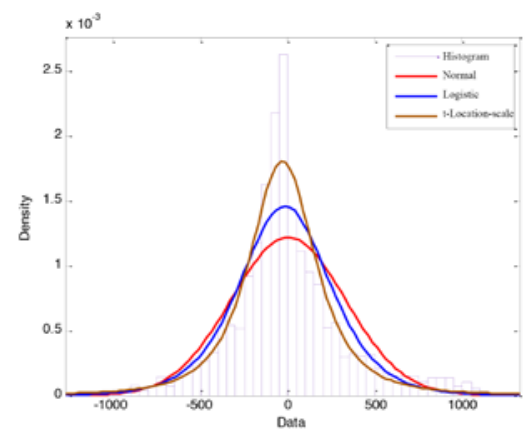

(c) 60 minutes' time scale

Fig.3. Comparison of probability density of PV output fluctuation at different time scales

Table 4 Comparison of different probability density function of PV output fluctuation under different time scales

\begin{tabular}{cccc}
\hline Time scale/min & t location-scale & normal distribution & logistic \\
\hline 1 & 0.1197 & 0.1601 & 0.0711 \\
2 & 0.0372 & 0.1030 & 0.0437 \\
5 & 0.0130 & 0.0796 & 0.0392 \\
10 & 0.0035 & 0.0246 & 0.0120 \\
20 & 0.0027 & 0.0149 & 0.0052 \\
30 & 0.0021 & 0.0104 & 0.0050 \\
40 & 0.0025 & 0.0046 & 0.0028 \\
50 & 0.0019 & 0.0037 & 0.0021 \\
60 & 0.0032 & 0.0034 & 0.0015 \\
90 & 0.0037 & 0.0039 & 0.0019 \\
\hline
\end{tabular}

It can be seen from Figure 3, figure 4 and table 4 that when the data time scale is the minimum 1min, the PV output fluctuation probability density fitting effects of three kinds of distribution functions are all poor, logistic distribution fitting effect is relatively good, within $2 \sim 60$ minutes time scale, With the increase of data time scale, the fitting effects of the 3 kinds of distribution functions are better and more stable, The fitting effect of $t$ location-scale distribution is the best of all, When the time scale is not less than 60 minutes, fitting results of logistic distribution is slightly better than the other two distribution functions. The fitting effect of the normal distribution is worse than that of the other two kinds at different time scales, but as the time scale increases, the fitting effect is gradually changed for the better, with the increase of the time scale, the probability distribution of the PV output fluctuations is closer to the normal distribution.

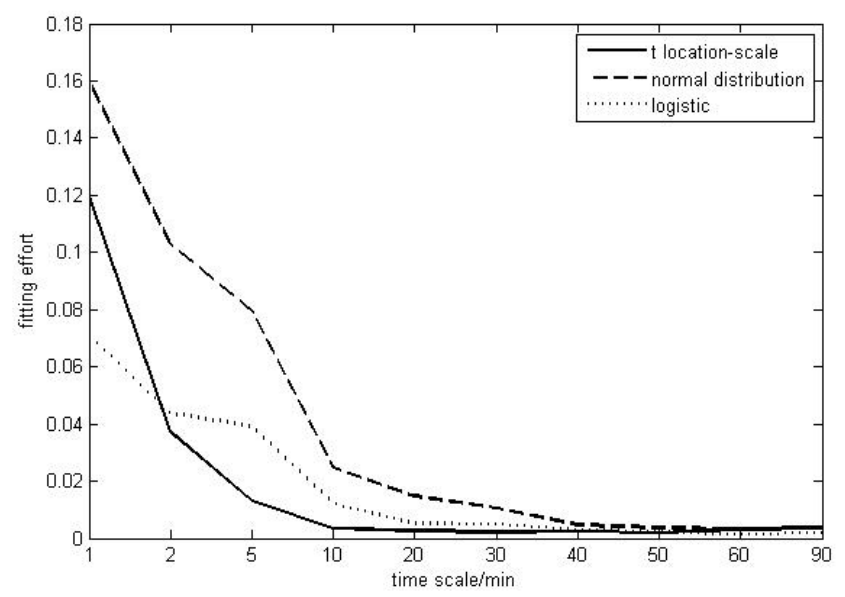

Fig. 4 Comparison of the fitting parameters of photovoltaic output fluctuation under different probability density function at different time scales 


\section{Conclusions}

Based on the historical data of photovoltaic power station, this paper analyzes the characteristics of photovoltaic output fluctuation at different time scales. The fluctuation level of PV output is analyzed quantitatively, and the random distribution characteristics of PV output fluctuation are studied by probability density fitting method, and the following conclusions are obtained:

(1) With the increase of time scale, the maximum fluctuation of PV output is also increased.

(2) The PV output fluctuation probability density fitting effects of three kinds of distribution functions are all poor at $1 \mathrm{~min}$ time scale, and logistic distribution fitting effect is relatively good.

(3) Within $2 \sim 60$ minutes' time scale, the fitting effect of PV output fluctuations probability density which is fitted by t location-scale distribution is the best of all.

(4) When the time scale is not less than 60min, fitting result of PV output fluctuation probability density which is logistic distribution is slightly better than the other two distribution functions.

\section{References}

[1] Sheng K, Kong L, Qi ZP, et al. A survey on research of microgrid-a new power system[J]. Relay, 2007, 35(12): 75-81.

[2] Schäfer B, Matthiae M, Timme M, et al. Decentral Smart Grid Control[J]. New Journal of Physics, 2015, 17(1).

[3] Widén J, Carpman N, Castellucci V, et al. Variability assessment and forecasting of renewables: A review for solar, wind, wave and tidal resources[J]. Renewable \& Sustainable Energy Reviews, 2015, 44:356-375.

[4] Giannuzzi G, Lauria D, Pisani C, et al. Real-time tracking of electromechanical oscillations in ENTSO-E Continental European Synchronous Area[J]. International Journal of Electrical Power \& Energy Systems, 2015, 64(4):1147-1158.

[5] Milan I, Dragan P, Sasa M. Primary, secondary and tertiary frequency control in dynamic security analyses of electric power interconnections[J]. Zbornik radova, Elektrotehnički institut “Nikola Tesla”, 2012(22):93-115.

[6] Zhao C, Low S. Optimal decentralized primary frequency control in power networks[C]// Decision and Control. IEEE, 2014:331-350.

[7] Teleke S, Baran M E, Bhattacharya S, et al. Rule-Based Control of Battery Energy Storage for Dispatching Intermittent Renewable Sources[J]. IEEE Transactions on Sustainable Energy, 2010, 1(3):117-124.

[8] Fripp M. Switch: a planning tool for power systems with large shares of intermittent renewable energy[J]. Environmental Science \& Technology, 2012, 46(11):6371-8.

[9] Kim Y S, Kim E S, Moon S I. Frequency and Voltage Control Strategy of Standalone Microgrids with High Penetration of Intermittent Renewable Generation Systems[J]. IEEE Transactions on Power Systems, 2015, 31(1):1-11.

[10]Tan K T, So P L, Chu Y C, et al. Modeling, control and simulation of a photovoltaic power system for grid-connected and stand-alone applications[C]// IPEC, Conference. IEEE, 2010:608-613.

[11] Seo H R, Kim G H, Jang S J, et al. Harmonics and reactive power compensation method by grid-connected Photovoltaic generation system[C]// International Conference on Electrical Machines and Systems. IEEE, 2009: 1-5.

[12] Patsalides M, Georghiou G E, Stavrou A, et al. Assessing the power quality behaviour of high photovoltaic (PV) penetration levels inside the distribution network[C]// IEEE International 
Symposium on Power Electronics for Distributed Generation Systems. 2012: 709-716.

[13]Hollinger R, Diazgranados L M, Braam F, et al. Distributed solar battery systems providing primary control reserve[J]. IET Renewable Power Generation, 2016, 10(1):63-70.

[14]Rikos E, Tselepis S, Hoyer-Klick C, et al. Stability and Power Quality Issues in Microgrids Under Weather Disturbances[J]. IEEE Journal of Selected Topics in Applied Earth Observations \& Remote Sensing, 2008, 1(3):170-179.

[15]Liserre M, Teodorescu R, Blaabjerg F. Stability of photovoltaic and wind turbine grid-connected inverters for a large set of grid impedance values[J]. IEEE Transactions on Power Electronics, 2006, 21(1):263-272. 